\title{
A case of persistent neonatal hyperinsulinaemic hypoglycaemia (nesidioblastosis)
}

\author{
A K Lamahewage ${ }^{1}$, E A N Fonseka ${ }^{2}$, S Illangakoon ${ }^{3}$ \\ Sri Lanka Journal of Child Health, 2004; 33: 27-8
}

(Key words: persistent neonatal hyperinsulinaemic hypoglycaemia, nesidioblastosis)

\section{Introduction}

Transient neonatal hypoglycaemia due to hyperinsulinism is seen commonly in infants of diabetic mothers, infants with erythroblastosis fetalis and in those with Wiedemann-Beckwith syndrome ${ }^{1}$. Persistent hyperinsulinaemic hypoglycaemia is rarer in neonate although it assumes increasing importance during first year of life to become the most common cause of severe hypoglycaemia in this age group ${ }^{2}$. The high incidence of mental retardation in survivors may be related to delayed diagnosis and to extreme difficulty experienced in controlling hypoglycaemia ${ }^{2}$.

\section{Case report}

A male infant, the first product of a nonconsanguineous marriage, was born at term by spontaneous vaginal delivery at the Kalutara General Hospital in September 2001. The birth weight was $2.6 \mathrm{~kg}$. There was no history of maternal diabetes mellitus. On the second postnatal day, the baby did not suck well, had a high-pitched cry and developed seizures. Subsequently, he developed acute respiratory distress and septicaemia and was transferred to the intensive care unit of the Lady Ridgeway Hospital for further management. He did not require ventilation and was transferred to a medical unit after initial stabilization.

The baby was jittery and continued to have frequent subtle and multifocal clonic seizures. His blood sugar was noted to be persistently below $2 \mathrm{mmol}$ per litre with both glucometer and laboratory assessment while on dextrose infusions $(10 \%, 12 \%, 15 \%)$ and boluses. Ultrasound scan of the abdomen showed a hypertrophied and enlarged pancreas but no evidence of a tumour. Computerized Tomography showed no abnormality. Insulin level was $92 \mu \mathrm{IU} / \mathrm{ml}$, more than three times the upper normal limit $(5-27 \mu \mathrm{IU} / \mathrm{ml})$.

\footnotetext{
${ }^{1}$ Consultant Paediatric Surgeon, ${ }^{2}$ Consultant Paediatrician, ${ }^{3}$ Senior House Officer in Paediatric Surgery, Lady Ridgeway Hospital Colombo,
}

(Received on 22 August 2003)
A provisional diagnosis of nesidioblastosis was made and a distal pancreatectomy carried out in October 2001. The histology (Figure 1) confirmed our diagnosis. As distal pancreatectomy did not help to stabilize blood sugar levels, most of the remaining pancreas was removed to achieve $95 \%$ pancreatectomy. The blood sugar level remained within normal range but there were subtle seizures for a few more days. Post-operative ultrasound scan of the brain revealed mild dilatation and deformity of the frontal lobe of the left lateral ventricle due to an area of ischaemia with associated atrophy.

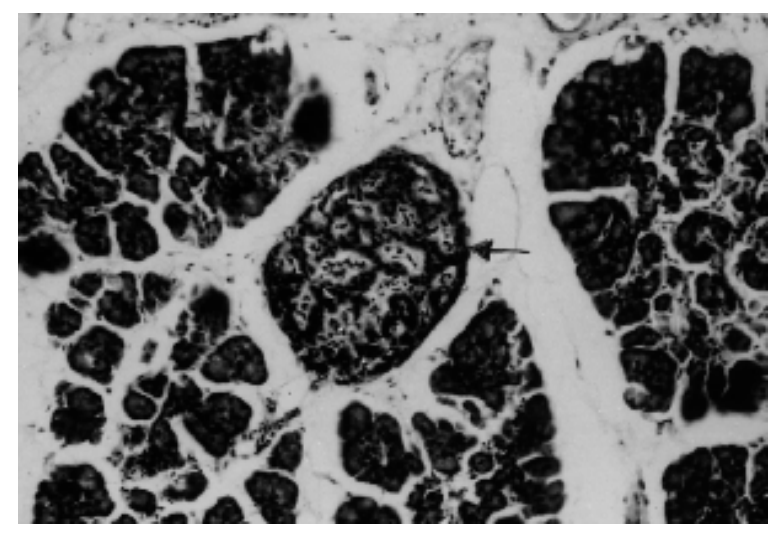

Figure 1. Haematoxil eosin stain; magnification $1 \times$ 400; hyperplasia of islet cells seen in the centre.

2 weeks after surgery, serum insulin level was 4.5 $\mu \mathrm{IU} / \mathrm{ml}$, below the normal range $(5-27 \mu \mathrm{IU} / \mathrm{ml})$. After surgery the dextrose infusions were tailed off and oral dextrose was given for a few days. Following the stoppage of dextrose, blood sugar levels remained in the normal range. The baby was discharged home with necessary instructions to the mother. He was last reviewed six months after surgery and was normoglycaemic, free of convulsions and thriving well with normal development.

\section{Discussion}

Nesidioblastosis is a term first used by Laidlaw in 1938 to indicate the formation of isolated endocrine cells and islets from pancreatic duct cells ${ }^{3}$. Brown 
and Young first reported the association of nesidioblastosis with severe infantile hypoglycaemia ${ }^{4}$. Persistent hyperinsulinism in infancy, whilst most commonly associated with diffuse abnormality of $\beta$-cell regulation, is also occasionally associated with focal disease such as isolated islet adenoma ${ }^{5}$. In the past, the term nesidioblastosis was applied to the non-focal type of disorder $^{5}$. More recently, the term has fallen into disfavour because the pattern is entirely nonspecific and can be found in the pancreas of newborn infants ${ }^{6}$. Today, the term 'nesidioblastosis' has been superseded by terms such as 'persistent neonatal hyperinsulinaemic hypoglycaemia' and 'persistent hyperinsulinaemic hypoglycaemia of infancy, .

Most cases are sporadic; however, familial forms appear to be inherited in an autosomal recessive manner ${ }^{7}$. There was no parental consanguinity in our patient. The primary feature of hyperinsulinism is recurrent episodes of symptomatic hypoglycaemia ${ }^{5}$. In severe cases hypoglycaemia occurs soon after or even despite feedings 5 . Signs and symptoms in neonates and young infants usually include seizures ${ }^{5}$. Frequent subtle and multifocal clonic seizures were present in our patient.

Inappropriately raised insulin levels for blood glucose concentration and requirement of high glucose infusion rates to maintain blood glucose level support a diagnosis of hyperinsulinism ${ }^{1}$. In our patient insulin level was $92 \mu \mathrm{IU} / \mathrm{ml}$ ( $>$ three times upper normal limit) whereas blood sugar was very low in spite of dextrose infusions $(10 \%, 12 \%, 15 \%)$ and boluses.

The immediate priority in treatment is to increase blood glucose concentrations to prevent convulsions and brain damage ${ }^{1}$. Treatment modalities include high glucose infusion rates, use of medications and surgical intervention. Diazoxide is the drug of first choice in hyperinsulinism as the large proportion of patients who respond do so fully and can be maintained on drug by mouth for many years 5 . Octreotide, a long-acting somatostatin analogue, is useful in short-term management of hypoglycaemia but due to problems with tachyphylaxis, has been effective as a chronic treatment in only a limited number of infants with severe hyperinsulism ${ }^{8}$. Although conservative management of persistent hyperinsulinaemic hypoglycaemia of infancy (PHHI) is very laborious for the family and the physician, it is recommended as long as euglycaemia is accomplished with these drugs 9 . Unfortunately these drugs are not available in Sri Lanka. It must be stressed that early pancreatectomy should be performed in those with inadequate maintenance of euglycaemia, prolonged course of medical therapy being feasible only in selected cases ${ }^{10}$. Surgical treatment includes subtotal to near total pancreatectomy with splenic preservation ${ }^{10}$. Complications from this procedure have been few, most commonly those associated with decreased insulin production (diabetes) at puberty requiring insulin ${ }^{11}$. Exocrine pancreatic deficiency requiring replacement therapy has also been reported. Other important short-term complication is inadequacy of resection, which may respond to oral nifedipine or surgery $^{12}$. Various types of intractable seizures and neurological sequelae have been reported ${ }^{13}$. Partial pancreatic regrowth has been evident at reoperation ${ }^{14}$.

\section{References}

1. Aynsley-Green A, Polak J M, Bloom S R, Gough $\mathrm{M} \mathrm{H}$ et al. Nesidioblastosis of the pancreas; definition of the syndrome and the management of the severe neonatal hyperinsulinaemic hypoglycaemia. Archives of Diseases in Childhood 1981; 56 : 496-508.

2. Baker L, Stanley C A. Hyperinsulinism in infancy; a pathophysiologic approach to diagnosis and treatment. In: Chimmello G, Laron $\mathrm{Z}$, editors. Recent progress in paediatric endocrinology. London: Academic Press, 1977: 89-100.

3. Laidlaw G F. Nesidioblastoma, the islet tumour of the pancreas. Am J Pathol 1938; 14: 125-34.

4. Brown R E, Young R B. A possible role for the exocrine pancreas in the pathogenesis of neonatal leucine-sensitive hypoglycaemia. Am J Dig Dis 1970; 15: 65-72.

5. Stanley C A. Hyperinsulinism in infants and children. Pediatric Clinics of North America 1997; 44 (2): 363-74.

6. Milner R D G. Nesidioblastosis unravelled. Arch Dis Child 1996; 74: 369-72.

7. Woolf D A, Leonard J V, Trembath R C et al. Nesidioblastosis. Evidence for autosomal recessive inheritance. Arch Dis Child 1991; 66: 29-30. 
8. Thornton P S, Alter C A, Levitt-Katz L E et al. Short and long-term use of octreotide in the treatment of congenital hyperinsulinism. $J$ Pediatr 1993; 123: 637-43.

9. Dacou-Vouteakis C, Psychon F, ManiatiChristidis M. Persistent hyperinsulinaemic hypoglycaemia of infancy; long-term results. Journal of Pediatric Endocrinology and Metabolism 1998; 11: 1131-41.

10. Parashar K, Upadhyay V, Corkery J J. Partial or near-total pancreatectomy for nesidioblastosis? [see comments] CM: Comment in: European Journal of Pediatric Surgery 1996; 6 (1): 55.

11. Chevalier S G. Nesidioblastosis : a case report. Connecticut Medicine 1996; 60 (6): 335-8.
12. Lindley K J, Dunne M J, Kane C, Shepherd R M et al. Ionic control of beta cell function in nesidioblastosis. A possible therapeutic role for calcium channel blockade. Archives of Diseases of Childhood 1996; 74 (5): 373-8.

13. Izumi $\mathrm{T}$, Takeshige $H$, Arai $\mathrm{T}$, Sugama $\mathrm{M}$ et al. Prospective study of nesidioblastosis in newborns and infants; hypoglycaemic seizures, epileptogenesis and the significance of the Cpeptide suppression test in pan-createctomy. Acta Paediatrica Japonica 1997; 39 (1): 10-7.

14. Rahmah R, Hayati A R, Kuhnle U. Management and short-term outcome of persistent hypoglycaemia of infancy (Nesidioblastosis). Singapore Medical Journal 1999; 40 (3): 151-6. 